Authors have nothing to disclose with regard to commercial support.

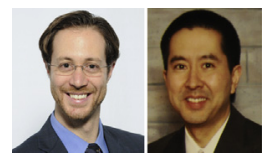

\section{REPLY: TRANSPARENCY OF JOB SEARCH NEEDS IMPROVEMENT:}

Reply to the Editor:

We recently commented ${ }^{1}$ on a study by Sterbling and colleagues, ${ }^{2}$ which reported the challenges that residents face when finding and securing a first job in cardiothoracic surgery. In the article, Sterbling and colleagues ${ }^{2}$ conclude that "resources, whether institutional or organizational, are sparse and difficult to tailor to individual needs." As outlined in a letter to the Editor by Luc and Antonoff, ${ }^{3}$ however, an abundant buffet of resources are availablefrom internet-based forums to society scholarshipsalthough, most of these opportunities are focused on the maturation of early-career surgeons. The topic of employment even has a "review" article, which presents the salient pearls of finding a first jobinformation many of the respondents seemingly asked for in a survey. ${ }^{4}$

All these resources (and innumerable others) were available at the time of the survey, suggesting that perhaps we have reached a threshold of diminishing returns. The poor response rate of Sterbling and colleagues' Internet-based survey ${ }^{2}(12.8 \%)$ reflects the limitation of passive, internet-based communication. Our interpretation of the article is that the employment process is largely dependent on who you know, rather than what you know, and that there continues to be a lack of transparency with regard to job opportunities, candidate selection, and job compensation. ${ }^{1}$ Optimization, in our view, therefore, depends on shifting energy away from adding to the deluge of resources and information to cultivating mentorship and expanding the connectivity of people. For example, there are a number of scholarships available through The American Association for Thoracic Surgery for residents to visit other institutions. Expansion of these opportunities, or even a shared expectation for residents to spend time at another institution at some point during training, would help expand perspectives and develop relationships. Admittedly, logistics would be a nightmare. Bolstering our expectations of mentorship is also essential. The type of "extreme mentoring" described by Pasque, ${ }^{5}$ for example, is an ideal, but it is difficult to establish given the required energy and dedication, often despite lack of monetary compensation. Perhaps development of strong mentors is an advantage to integrated training models (I6, 4:3), given the longer duration and educational investment of these programs.
It is our hope that Sterbling and colleagues ${ }^{2}$ follow up their data with further investigation, to determine whether current interventions have improved in the process of job search for our residents over time and to evaluate the 5-year survival (and quality of life) of an initial job in cardiothoracic surgery. These data would provide us with greater insight into the experience of finding the right first job and how to thrive as an early career surgeon.

Travis C. Geraci, $M D^{a}$

Thomas $\mathrm{Ng}, \mathrm{MD}^{b}$

${ }^{a}$ Department of Cardiothoracic Surgery

New York University_Langone Health

New York, $N Y$

${ }^{b}$ Department of Surgery

Warren Alpert Medical School of Brown University

Providence, $R I$

\section{References}

1. Geraci TC, Ng T. Commentary: finding a job in cardiothoracic surgery: is it who you know rather than what you know? J Thorac Cardiovasc Surg. 2019; $158: 642-3$

2. Sterbling HM, Molena D, Rao SR, Stein SL, Litle VR. Initial report on young cardiothoracic surgeons' first job: from searching to securing and the gaps in-between. J Thorac Cardiovasc Surg. 2019;158:632-41.e3.

3. Luc JGY, Antonoff MB. Bridging gaps in transition to practice. J Thorac Cardiovasc Surg. 2019;158:e177.

4. Macke RA, Ghanta R, Starnes S, Harken AH. So, you are looking for a job: pearls for a successful first cardiothoracic job search. J Thorac Cardiovasc Surg. 2018; $156: 1575-84$.

5. Pasque MK. Extreme mentoring in cardiothoracic surgery. J Thorac Cardiovasc Surg. 2015;150:785-9.

https://doi.org/10.1016/j.jtcvs.2019.06.051

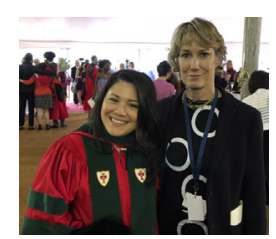

REPLY: LEADING

THE WAY IN

CARDIOTHORACIC

SURGERY CAREER

DEVELOPMENT:

\section{Reply to the Editor:}

It was with great pleasure that we read Luc and Antonoff's letter commenting on our article, "Initial Report on Young Cardiothoracic Surgeons' First Job: ${ }_{1}$ From Searching to Securing and the Gaps in Between." With different perspectives on cardiothoracic (CT) surgery careers, one from a CT surgery resident's standpoint and the other from a highly productive early-career academic CT surgeon, the previous letter was able to highlight resources available for future career planners, job seekers, and early career professionals alike. Recognizing the remarkable efforts and initiatives put forth by individuals and professional organizations within the CT surgery sphere is important. The call for early career mentoring is 